\title{
Aa.Vv, L'œil de la NRF. Cent livres pour un siècle
}

\section{Gabriella Bosco}

\section{OpenEdition}

\section{Journals}

\section{Edizione digitale}

URL: http://journals.openedition.org/studifrancesi/7778

DOI: 10.4000/studifrancesi.7778

ISSN: 2421-5856

\section{Editore}

Rosenberg \& Sellier

\section{Edizione cartacea}

Data di pubblicazione: 1 décembre 2009

Paginazione: 687

ISSN: 0039-2944

Notizia bibliografica digitale

Gabriella Bosco, «Aa.Vv, L'œil de la NRF. Cent livres pour un siècle», Studi Francesi [Online], 159 (LIII | III) | 2009, online dal 30 novembre 2015, consultato il 09 janvier 2021. URL: http://

journals.openedition.org/studifrancesi/7778 ; DOl: https://doi.org/10.4000/studifrancesi.7778

Questo documento è stato generato automaticamente il 9 janvier 2021.

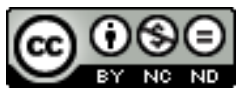

Studi Francesi è distribuita con Licenza Creative Commons Attribuzione - Non commerciale - Non opere derivate 4.0 Internazionale. 


\title{
Aa.Vv, L'œil de la NRF. Cent livres pour un siècle
}

\author{
Gabriella Bosco
}

\section{NOTIZIA}

AA.VV, L'œil de la NRF. Cent livres pour un siècle, Paris, Gallimard, 2009, pp. 351.

1 Per celebrare i cento anni di una rivista specchio del suo tempo, "La Nouvelle Revue Française", protagonista di un'avventura intellettuale straordinaria fatta di critica militante aperta alla varietà e al pluralismo, le edizioni Gallimard pubblicano un volumetto che raccoglie le cento recensioni più significative del secolo, i cento saggi pubblicati nelle pagine della mitica NRF a presentare libri che hanno segnato il Novecento.

2 Ad aprire la raccolta, il testo che il fondatore della rivista André -Gide scrisse il primo febbraio 1909 sui Poèmes pour un riche amateur di Valéry Larbaud («Ce livre est fait pour irriter les uns, amuser d'autant plus les autres; hâtons-nous d'être de ceux-ci» sono le prime parole della recensione). Vi troviamo articoli diventati famosi come quello che racconta della scoperta da parte di Mauriac lettore de La Prisonnière di un altro Proust, o dell'entusiasmo di Cocteau per Le diable au corps di Radiguet; il saggio in cui Malraux studia l'erotismo de L'Amante di lady Chatterley, quello in cui Robbe-Grillet riconosce nella Coscienza di Zeno un tempo malato e quello in cui Pieyre de Mandiargues sottolinea l'originalità del Barone rampante di Italo Calvino. Ma anche le pagine di Breton sui Chants de Maldoror di Lautréamont e quelle di Benjamin Crémieux su Chéri di Colette, di Pierre Mac Orlan su Martin Eden di Jack London, di Ramón Fernández su Lord Jim di Joseph Conrad, di Raymond Queneau su Tropic of Cancer di Henry Miller e di Jean-Paul Sartre su Sartoris di William Faulkner. O ancora di Michel Butor su Celui qui ne m'accompagnait pas di Maurice Blanchot, come pure le pagine di Pietro Citati su L'identité di Milan Kundera. Giù per il secolo fino all'ultimo saggio che recensisce Dans le café de la jeunesse perdue di Patrick Modiano, scritto da Paul Gellings nel gennaio scorso. 
3 Ci accorgiamo così anche del fatto che se la NRF ha pubblicato un gran numero di testi di scrittori già confermati, è però anche stata il luogo in cui si sono forgiati il pensiero e lo stile di numerosi autori: Malraux aveva vent'anni quando vi firmò la sua prima nota, Philippe Jaccottet ventotto e Robbe-Grillet trenta. Il volume è corredato da una sezione di brevi, utili notizie biografiche sugli autori raccolti. 